\title{
Os Cadernos de Teatro \& A Descentralização do Saber Teatral
}

José Ronaldo Faleiro

Universidade do Estado de Santa Catarina

Fundados em 1956, os Cadernos de Teatro d'O Tablado completam quarenta e cinco anos em 2001. Procuro neste artigo as origens inspiradoras desse periódico e algumas de suas repercussões.

\section{As origens}

Numa entrevista a mim concedida em 1993, Maria Clara Machado confirma que o nome da publicação é inspirado no dos periódicos que Chancerel publicou de 1945 a 1950, intitulados Cahiers d'Art Dramatique [Cadernos de Arte Dramática]. Sua fundadora tomou conhecimento deles durante a sua primeira permanência na França. Tendo lido esses cadernos, sentiu vontade de fazer publicações periódicas no mesmo espírito:

JRF - Você conheceu Chancerel através do movimento escoteiro?

MCM - Não. Não. Fui até lá, quer dizer ao Centro Léon Chancerel ${ }^{1}$. Fui lá e comprei os Cahiers [Cadernos].

JRF - Em suma, Maria Clara, você foi recebida no Centro Dramático de Chancerel, você leu na França os Cahiers d'Art Dramatique de Chancerel, e...

MCM - ...e tive vontade de fazer igual. A tal ponto que são Cadernos, também (FALEIRO, 1998:421 e 446).

\footnotetext{
${ }^{1}$ Situado no número 98 do Boulevard Kellermann, Paris 13e, o Centro Dramático foi a residência e o local de trabalho de Léon Chancerel desde seu regresso de Toulouse, em 1945, após o término da Segunda Guerra Mundial, até sua morte, em 1965. Aí desenvolveu as atividades da Associação Centro Dramático, por ele fundada. Hoje em dia esse prédio de dois andares e um porão continua a abrigar a biblioteca Léon Chancerel e as sedes da Société d'Histoire du Théâtre [Sociedade de História do Teatro] e da Association Internationale de Théâtre pour l'Enfance et la Jeunesse/ASSITEJ [Associação Internacional de Teatro para a Infância e a Juventude], ambassob o impulso de Rose-Marie Maudouès, colaboradora de Chancerel. Localiza-se muito próximo à Cidade Universitária Internacional, que foi um dos lugares onde viveu Maria Clara Machado
} 
A questão do teatro popular e da popularização do teatro, da ampliação da presença do teatro para além dos grandes centros - a descentralização - é discutida na França desde pelo menos o final do século XIX. Maurice Pottecher funda o seu Teatro do Povo na cidade de Bussang, na floresta dos Vosgos, em 1895. Já nos primórdios do século XX, Romain Rolland publica Le Théatre du Peuple [O Teatro do Povo], em 1903. Nas duas primeiras décadas do século XX, Firmin Gémier viaja pelo interior com o seu Teatro Nacional Ambulante. As discussões e experimentos sobre o assunto seguem o seu curso ao longo da primeira metade do século. Em 1941, Jacques Copeau publica O Teatro Popular. Depois da Segunda Guerra Mundial, a descentralização se concretiza em território francês, com a implantação dos centros dramáticos regionais. A s idéias e práticas de Jacques Copeau e de Léon Chancerel muito contribuíram para formar as equipes que estariam aptas a atuar, desde 1946, neste novo fronte. Nesse movimento, a palavra escrita foi elemento valioso.

Chancerel declara, em seu Bulletin d'Information et de Liaison [Boletim de Informação e de Ligação] (1955-1956), que deve a Jacques Copeau a idéia de publicar uma revista. Querendo renovar a vida e a cena francesas, dar-lhes "verdadeiros valores", Copeau amplia o seu campo de ação, pensando a formação dos atores dentro de uma "pedagogia total", e tornando o VieuxColombier (teatro e escola) um centro de cultura geral. Concebe e amadurece, durante a Primeira Guerra Mundial, o projeto dos Cahiers.

Não se trata, evidentemente, de uma idéia original. Na realidade, no século XIX Richard Wagner havia fundado o Bayreuther Blätter, e André Antoine publicara (1887-1894) suas cinco brochuras du Théâtre Libre. Paul Fort cria a seguir o periódico do Théâtre d'Art (sete números, 1891-1892), et Lugné-Poe publica L'Oeuvre (noventa números, 1909-1930). Por fim, Max Reinhardt funda na Alemanha (1911) son Blätter des Deutches Theaters, retomado depois em Viena com o título de Blätter des Theaters in des Josefstadt. Talvez, porém, sejam os Cahiers de la Quinzaine, de Charles Péguy, que tenham inspirado Copeau mais diretamente: Péguy também deseja

na capital francesa, durante sua temporada parisiense de 1949-1950. Na carta de "Paris, 1.2.50", Maria Clara conta ao pai, o escritor Aníbal Machado, que se instalou na Cidade Universitária, num quarto amplo com um parque visto da janela, compartilhado com Sílvia Moscovici, "uma pessoa muito silenciosa"... Na carta parisiense datada de 25.3.50, endereçada a toda a família, sacia a curiosidade do pai, escrevendo que, de trem (pela linha de Sceaux), chega em quinze minutos ao "curso Barrault", no Boulevard Raspail. Terá levado ainda menos tempo, a pé, para ir ao Centro Dramático de Chancerel: o Boulevard Jourdan, que passa em frente à Cidade Universitária Internacional de Paris, é a continuação do Boulevard Kellermann. 
reconstruir um público na um grande periódico, que constituísse aos poucos uma espécie de enciclopédia do saber teatral. Disse um dia a Louis Jouvet ${ }^{2}$ que era preciso estar na primeira fila com um palco e um jornal. Transmite esse desejo a Léon Chancerel, que durante a vida inteira se esforçará para se desincumbir da tarefa, com tenacidade, movendo-se e epermanecendo o mesmo, como o moinho que ilustra algumas de suas publicações - « in sua movenza e fermo » (CAHIERS D’ART DRAMATIQUE, 1950c:88).

Assim, "transplantados" para o Brasil por Maria Clara Machado, os opúsculos de Chancerel foram certamente de grande auxílio para a adaptação desse movimento junto à realidade brasileira do imediato pós-guerra.

Com efeito, a primeira preocupação da equipe d'O Tablado que lançou os Cadernos de Teatro diz respeito aos grupos novos que se formam nos lugares mais recuados do Brasil e buscam iniciar-se no mundo teatral e ampliar seus conhecimentos sobre ele. Sua divisa é Remember Amapá ${ }^{3}$, um modo bemhumorado de falar em descentralização do teatro...

Partir da própria realidade para depois difundi-la é outro elemento fundamental no procedimento de ambos os líderes. O grupo teatral O Tablado pôs cinco anos, de 1951 a 1956, para fundar sua revista, os Cadernos de Teatro. Sentiu necessidade de realizar seus próprios experimentos e suas próprias pesquisas antes de se julgar capaz de transmitir a outros o seu conhecimento. A revista surgiu, na verdade, dentro de uma equipe teatral já bem conhecida do público e da crítica do Rio de Janeiro. Críticos dramáticos louvavam-lhe então a novidade, a qualidade ou o caráter coletivo. Assim, em 1952, Paschoal Carlos Magno escreve que $\mathrm{O}$ Tablado the revelou um modo de fazer teatro que ele só vira anteriormente nos jovens ingleses de Cambridge, no grupo de Vittorio Gassmann, nos Pitoëff ou em alguns grupos da Inglaterra (MAGNO, 1986:174; Claude Vincent, em 1955, observa que as decisões do grupo são tomadas

\footnotetext{
${ }^{2}$ Jouvet também teve a sua revista, Entr'acte, publicada pela Comédie des Champs-Elysées (1927-1928). Du Théâtre Libre au Théâtre Louis Jouvet. Les Théâtres d'Art à travers leurs périodiques [Do Teatro Livre ao Teatro Louis Jouvet. Os Teatros de Arte através de seus periódicos] estuda as seguintes publicações: Le Théâtre Libre [O Teatro Livre], Le Théâtre d'Art [O Teatro de Arte], L'Oeuvre [A Obra], Les Cahiers du Vieux-Colombier [Os Cadernos do Vieux- Colombier], La Chimère [A Quimera], Correspondance [Correspondência], Entr'acte [Entreato] (VEINSTEIN, 1955).

${ }^{3} \mathrm{Na}$ época da fundação dos Cadernos de Teatro, o Brasil contava com vinte estados, um Distrito Federal e cinco territórios. Situado na fronteira com as então Guianas (Francesa, Inglesa e Holandesa), o Amapá era um território. Para os jovens do Rio de Janeiro dos anos cinqüenta, ele era o símbolo de tudo o que houvesse de mais distante no espaço e de menos desenvolvido do ponto de vista cultural.
} 
democraticamente e todos os membros da equipe trabalham pelo sucesso comum (VINCENT, 1955:175). O grupo poderia ter optado por fazer uma publicação sofisticada, dirigida exclusivamente para o meio teatral do Rio de Janeiro, que era então a capital do país. Mas assim não aconteceu. O Tablado preferiu dialogar com o público a quem pretendia dirigir-se.

Trata-se realmente de um diálogo? Por um lado há o conteúdo da revista; por outro, há reflexões, aplicações, os textos dos leitores. O que se estabelece não é um diálogo somente epistolar, escrito. É também um contato que se constrói, da parte do leitor, no desejo de pôr em prática o que foi lido, estabelecendo assim uma relação viva com o teatro, criando uma necessidade de servir à arte.

No intermédio, na junção entre leitores e artistas, os Cadernos de Teatro expõem, antes de mais nada, não uma doutrina, mas uma prática.

As idéias que a subtendem nem por isso estão menos presentes. No primeiríssimo número da revista, mencionando a grande efervescência teatral então vivida pelo país, Maria Clara Machado afirma que da mistura da lição dos antepassados, da experiência dos grupos e da experiência externa se forma pouco a pouco um teatro no

Brasil. Expressa a firme convicção de que os conselhos dos mestres que que passaram a vida inteira tentando resolver os problemas da vida teatral podem ser úteis aos que estão iniciando. Baseando-se em Charles Dullin — para quem são os próprios deuses que nos fazem faltam, e não as máquinas para fazer com que desçam de seu mundo ${ }^{4}$ —, acredita que não é possível fazer teatro sem técnica, mas que essa técnica deve ser vivificada por um espírito de teatro. São prioridades: não esquecer as pequenas cidades do Brasil e divulgar tudo o que diga respeito à formação corporal do ator, à encenação, à técnica da cena, para chegar a uma cultura teatral e à formação de um espírito de grupo. Portanto, preparar o ator ao mesmo tempo em que preparar a pessoa do ator.

Nos primeiros números, os Cadernos de Teatro não escondem quequase todos os seus artigos são traduções ou adaptações. Seus fundadores declaram não se sentir ainda bastante capazes de emitir suas próprias opiniões. Preferem adaptar a suas necessidades o pensamento e a experiência daqueles que os

\footnotetext{
${ }^{4}$ Nessa afirmação de Charles Dullin podemos perceber o eco da luta de Jacques Copeau, seu mestre, por um "tablado nu”, expresso já no seu manifesto publicado pela Nouvelle Revue Française/NRF [Nova Revista Francesa] no momento da fundação do Teatro do Vieux-Colombier, em 1913. Procurando renovar o teatro e dar importância à poesia no teatro, em seus escritos Copeau indignava-se, entre outras coisas, com os aplausos que os cenários arrancavam do público.
} 
auxiliaram a começar.

Já foi dito que tanto Maria Clara Machado quanto Léon Chancerel tiveram objetivos semelhantes: formar uma equipe e preparar movimentos ligados à juventude para um trabalho especificamente teatral. Chancerel e sua equipe consignaram no Bulletin des Comédiens Routiers (1932-1935), em Art Dramatique (1935-1938), nos Cahiers d'Art Dramatique (1945-1950), e também no modesto Bulletin d'Information et Liaison (1955-1956), um testemunho rico de seu trabalho, que pode ainda servir aos leitores em busca de formação teatral. É oportuno recordar aqui algumas idéias obtidas em sua leitura.

\section{Princípios e práticas nos Cahiers/Cadernos}

Primeiramente, o treinamento físico, corporal e vocal. Chancerel considerava-o fundamental. Para ele, os exercícios que põem em ação o corpo são globais, mobilizando-o integralmente, sem acentuar uma parte em detrimento de outra, nem fazer trabalhar mecanicamente. A preocupação de não queimar etapas é evidente, pois "só se passará à improvisação depois de haver consolidado muito bem a sintaxe corporal" (BULLETIN DES COMÉDIENS ROUTIERS D'ILE DE FRANCE, 1932:13)

Utilizando o método do tenente Hébert ${ }^{5}$, as sessões de trabalho começam com alguns minutos (de dez a trinta) destinados a mover o corpo, a caminhar e a fazer acrobacia, para obter controle, maleabilidade e equilíbrio corporais. Esses exercícios são executados em grupo. Considerados "elementares", propõem ações como caminhar em fila, ao som de um tambor, com variação de ritmos; caminhar embaixo de um sol tórrido, caminhar na chuva, caminhar na montanha ou numa cidade; fazer caminhadas ritmadas em relação com um elemento exterior imaginário (recuar ou avançar por influência de uma força sobrenatural) ou a partir dos animais. Depois, rir cada vez mais, até chegar às gargalhadas (seja individual, seja coletivamente, com a propagação do contágio), colher flores, lavar roupa no rio, resistir ou ceder ao sonho.

Partindo desses exemplos, que formam quase imperceptivelmente o

\footnotetext{
${ }^{5}$ Tendo muito viajado e muito observado, Georges Hébert criou o "hebertismo", método global que ensina a treinar o corpo pela execução dos "dez exercícios naturais": caminhar, correr, saltar, praticar a quadrupedia, trepar, levantar-carregar, lançar, atacar-defender, equilibrar-se, nadar. Tal método permite a aquisição de grande resistência física, muito necessária ao ator (BAYEN, 1945:23). Seu método foi utilizado no Teatro e na Escola do Vieux-Colombier. Portanto, Jean Dasté, Marie-Hélène Dasté, Etienne Decroux, Charles Dullin e Louis Jouvet, entre outros, tomaram conhecimento de seus princípios e praticaram tais exercícios.
} 
sentido do grupo, os participantes têm a tarefa de inventar, por sua vez, exercícios, jogos, temas, cuja expressão se encarregarão de aprofundar cada vez mais: Dominar o corpo para torná-lo um instrumento perfeito. Flexibilidade, equilíbrio, fôlego e ritmo são as qualidades fundamentais. Depois, começa-se a dramatizar os exercícios de escola. Estuda-se o gesto augusto do semeador, as inúmeras maneiras de caminhar (...) Entrar no mar num lugar levemente inclinado. Nada de anedota, nada de arrepio se a água estiver muito gelada. $\mathrm{O}$ essencial: a música do corpo... O corpo pode também tornar-se árvore, rochedo, animal pré-histórico (HUSSENOT, 1978: 44).

Em cena, o mais importante não é saber falar: é saber calar. Em cena, o jogo do ator consiste em falar e ouvir. Ele não pode falar sem representar mas pode representar sem falar. A reação corporal ao meio ambiente, a aquisição da maleabilidade, o sentido do ritmo e da observação são os objetivos procurados pelo trabalho e reiterados nas publicações de Chancerel.

A partir do treinamento corporal em grupo, forma-se pouco a pouco o espírito coletivo, de equipe, a formação coral, "orquéstica"'6.

Quanto à voz, os periódicos franceses aludidos não apresentam muitos exemplos de treinamento. Há exemplificação de certos exercícios simples de pronúncia ou dicção, ou de canto seguindo um ritmo, como na "Marcha para o Suplício" (BULLETIN DES COMÉDIENS ROUTIERS D'ÎLE DE FRANCE 1933:134-36). Há também interesse pela onomatopéia, arte estudada pelos alunos da Escola do Vieux-Colombier (1920-1924) e batizada como "grommelot" [gromelô].

Os exercícios vocais, como os corporais, contribuem para a formação do coro e, por isso mesmo, para a formação de todos os membros da equipe. Às vezes movimento e voz são trabalhados conjuntamente, como nas caminhadas concomitantes com a emissão de um som coincidente com o ritmo do andar.

Na execução dos exercícios, deve-se evitar a caricatura, o excesso, o que desvio da economia, e sobretudo procurar a expressão do corpo, sua "música", "o jogo perfeito dos músculos, a continuidade e o encadeamento

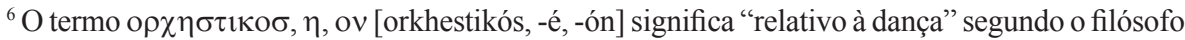
Platão de Atenas (430-348 a.C.), Leis 816 a. Para o filósofo e biógrafo Plutarco de Queronéia (205-270 d.C.), Marius 27 b, 67 b, trata-se de "quem se entrega à dança". - O substantivo $\eta$

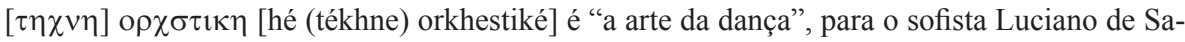
mosata (c.120-200 d.C.), Salt. 65, 71 [Da Arte da Dança]. - “Os 'jogos dramáticos', praticados desde a infância, são o caminho que se deve trilhar para estabelecer essa orquéstica de que já se podem entrever as conseqüências magníficas, na obra de reconstrução a que estamos atrelados" (CHANCEREL, [1936]: 10). 
sem choque das atitudes" (BULLETIN DES COMÉDIENS ROUTIERS D'ÎLE DE FRANCE, 1932:13).

Trata-se, portanto, não de uma inspiração, mas de um trabalho técnico, corporal, mobilizador dos músculos e da totalidade do ser. Esse treinamento físico apropriado visará, porém, mais ao desenvolvimento harmonioso de todo o indivíduo do que somente a melhorar uma parte do corpo considerada isoladamente.

Em suma, os exercícios constantes dos periódicos publicados por Léon Chancerel vão ajudar a imprimir num grupo ou num ator um tipo de jogo baseado no corpo, onde a voz é utilizada apenas quando absolutamente necessária, tornando-se esta, portanto, um elemento integrado ao corpo e ao ritmo. Chega-se, com isso, a um jogo não naturalista, que dispensa os cenários e permite que o ator represente seres humanos ou não humanos, assim como todos os tipos de mundos imaginários. O que é buscado - e expresso nas páginas dos periódicos em estudo - é o instinto e a invenção dramáticos do aluno; o poder pessoal da expressão do corpo e da mímica; o sentido da personagem e da situação; a formação do ator como um ser humano.

Nesse conjunto, a improvisação é empregada como método de formação e como recurso para a criação de personagens, e é executada, para preparar o ator a jogar, a partir de exercícios de treinamento do corpo e da voz; a partir de temas; a partir de personagens (da Commmedia dell'Arte e outras); e a partir de situações (também da Commmedia dell'Arte e outras).

Intimamente vinculada ao trabalho do corpo em silêncio e em estado de improvisação, o uso da máscara é um instrumento para a aprendizagem dramática a ser utilizado na sala de trabalho (ateliê) antes de o ator passar a representar com máscara diante dos espectadores. Supõe e impõe uma interpretação muito física, e até acrobática. Por isso está estreitamente ligado aos exercícios para treinar o corpo e a voz (e, portanto, a rapidez dos reflexos, a observação e a reação, a presença no espaço de representação, o contato com os colegas, a precisão do movimento ).

Olivier Hussenot apresenta sete razões para utilizar a máscara: evitar a maquilagem; ajudar o ator; poder representar todos os papéis, independentemente da idade ou do tipo físico; mudar de personagem segundo as necessidades do grupo; representar papéis do outro sexo; desdobrar, multiplicar o jogo dos intérpretes; facilitar a passagem de uma personagem para outra (HUSSENOT, 1932:8-9).

No início de seu artigo, Hussenot declara haver um preconceito na França, na época, em relação a trabalhar com máscaras. É inegável a influência dos 
periódicos de Chancerel para a mudança dessa atitude.

De fato, através das publicações sobre a máscara surgidas nos Bulletins des Comédiens Routiers, em Art Dramatique et nos Cahiers d'Art Dramatique, os leitores puderam aperfeiçoar e às vezes modificar suas concepções referentes ao teatro, como o demonstra este depoimento de um leitor, confirmando a contribuição desses periódicos como uma espécie de escola à distância:

Leitor assíduo do Bulletin des Comédiens Routiers, primeiro pensei que a arte da máscara e o jogo com máscara deviam ser algo muito estranho. Depois, lendo o Bulletin, minha opinião se modificou, mas outra objeção se apresentou a meu espírito, para nós que estamos no interior, distantes de Paris. Como fazer para, sozinhos, fabricar máscaras? O Bulletin veio me socorrer, e tentei (...), partindo de uma máscara de cartolina comprada na cidade e transformada por nós. Agora estamos mais do que convencidos: entusiastas. E devemos essa transformação, essa metamorfose de nosso gosto teatral, a vocês. Nosso muito sincero obrigado (BULLETIN DES COMÉDIENS ROUTIERS D'ILE-DE-FRANCE, 1933:276-277).

Portanto, é possível afirmar que os periódicos de Léon Chancerel atingiram seu objetivo de informar e sobretudo formar à distância leitores interessados no fato teatral ${ }^{7}$.

Dos Cahiers aos Cadernos

Inspirando-se nos Cahiers d'Art Dramatique [Cadernos de Arte Dramática] (1945-1950) de Léon Chancerel, fundador da Associação Centro Dramático, em Paris, Maria Clara Machado teve, portanto, como já foi dito, a idéia de fundar, no Rio de Janeiro, os Cadernos de Teatro do grupo O Tablado. Não conheceu o Bulletin des Comédiens Routiers (1932-1935) nem Art Dramatique (1935-1938). Todas as traduções dos artigos provêm dos Cahiers.

Do ponto de vista do trabalho do ator, até o número 19, podemos contatar traços nítidos da influência do periódico francês sobre o brasileiro. A presença dos autores franceses é considerável, através da tradução de artigos ou de trechos de artigos ou de livros publicados nos Cahiers d'Art Dramatique, ou pela publicação de autoresque se situam na mesma esfera de pensamento que

\footnotetext{
${ }^{7}$ Sobre os efeitos formadores do Bulletin, um leitor envia um relatório pormenorizado de suas atividades de

"teatro no colégio" e afirma, no item 2 , que "durante as sessões de estudo, o trabalho era dividido da seguinte maneira: 20 minutos de exercícios de formação coral segundo a técnica proposta pelo boletim dos Comédiens Routiers [Atores Itinerantes] (...)»(GARRONE, 1938:82-94.)
} 
Chancerel, como JacquesCopeau, Louis Jouvet, Jean Dasté, Michel SaintDenis, Charles Dullin, Gaston Baty, Georges Pitoëff, Jean Vilar. Seus leitores podem, assim, praticar exercícios corporais e vocais, jogos dramáticos, técnicas de encenação a partir dos escritos de Charles Antonetti, de Jan Doat, de Henri Cordreaux, de Hélène Charbonnier-Joly e de Anne-Marie Saussoy-Hussenot, de Jacques Lecoq e do próprio Chancerel. Essa presença se rarefez com o tempo, mas nunca desapareceu totalmente.

$\mathrm{Na}$ verdade, com Chancerel, no cerne da prática de Maria Clara Machado e da orientação que imprimiu aos Cadernos de Teatro está a convicção de que todo conhecimento deve poder ser utilizado, e que é preciso evitar a erudição sem a prática. Ainda com Copeau e Chancerel, para Maria Clara o desejo de contribuir para renovar o teatro do seu tempo passa por uma exigência de qualidade que visa a obter dos atores amadores um resultado tão apurado que chegue a influenciar a ética e a estética dos atores profissionais. As idéias dos Cadernos sobre a questão são expostas através dos artigos traduzidos, em grande parte. Assim, no número 1, após o manifesto de "MCM", uma citação de Théodore de Banville se refere à representação dramática e à comunhão com o público. Chancerel aparece na página 4, numa citação enquadrada: "Para a felicidade de um grupo, e ao mesmo tempo no interesse dos espetáculos, será preciso estabelecer um equilibrio entre a arte e a vida. Nem sempre é fácil". No mesmo número, em forma de versos, o mesmo autor dita os dez mandamentos do encenador e os dez mandamentos do ator, acompanhados de uma nota da redação do periódico brasileiro que sublinha a utilidade desses preceitos (CADERNOS DE TEATRO, [1956]:6-7) ${ }^{8}$. Para o ator, trata-se de aprender seu texto longa e perfeitamente; de chegar na hora para os ensaios; de não beber demais para poder representar (!!!); de odiar a cabotinagem; de se regozijar também com o sucesso dos outros; de ser disciplinado, não tagarela ou inconveniente; de aceitar com modéstia os cumprimentos. $\mathrm{O}$ quinto mandamento faz menção ao treinamento quotidiano do corpo e da voz. A página 5 acolhe quatro parágrafos de Jacques Copeau sobre o público. No mesmo número, Charles Dullin sublinha a importância de respirar bem e de falar bem (id., ib.:8-9).

\footnotetext{
${ }^{8}$ Em seus primeiros números, é frequente os Cadernos de Teatro não indicarem a fonte completa ou não darem nenhuma indicação sobre a procedência das matérias $>$ Assim, somente após a leitura atenta das duas coleções pode-se afirmar que a citação asima é oriunda do Suplemento "Comment monter et présenter un spectacle de qualité" [ Como montar e apresentar um espetáculo de qualidade], Cahiers d'Art Dramatique ]Cadernos de Arte Dramática], publicação da Association Centre Dramatique [Associação Centro Dramático], ano 10, n. 5, p.20-21, jun. 1948.
} 
Desde o primeiro número os Cadernos lembram os Cahiers, também pela diagramação, pelo formato, pelas citações, pela organização dos conteúdos, pelo tipo de enfoque. Nos Cahiers, Chancerel publica uma coluna intitulada "Formação do Ator"; Maria Clara, nos Cadernos, uma coluna cuja denominação oscila entre "Escola do Ator", "Jogos Dramáticos”, "Exercícios práticos do ator". Como Chancerel — que, quando Maurice Jacquemont deixou o grupo, manifestou-se contra a profissionalização dos Comédiens Routiers -, Maria Clara num momento de crise no Tablado publica, no número 6, um artigo sobre essa questão que pode ser útil para muitos outros grupos de teatro amador.

Um aspecto fecundo dos Cadernos de Teatro é, portanto, a sua noção de continuidade. Ao formar formadores ou atores, uma cadeia se estabelece. Um tipo de trabalha continuará. Cada um é um elo numa sucessão, numa família, numa tradição. Grotowski gostava de citar monges orientais que diziam que o discípulo deve superar em pelo menos vinte por cento o mestre. O que importa é a obra a construir, o que não se faz numa ou duas gerações (nem numa só coleção de periódicos...). Tenir et poursuivre [Manter e continuar] foi uma divisa em certos instantes dramática para ambos os criadores, mas, livre dos entraves que às vezes acarreta, pode iluminar um trabalho que se consagra à causa do teatro com a finalidade de aproximar as pessoas.

Outro aspecto fecundo desse trabalho consiste no fato de pôr generosamente à disposição do leitor uma série de artigos sobre o ator, o corpo, a voz ou a encenação, que possibilitaram a muitos amadores brasileiros encontrar o seu caminho e até se tornarem profissionais na área. Para citar apenas um, é o caso do encenador Paulo Affonso Grisolli, que declara num artigo ter aprendido muito, jovem estudante, nas páginas dos Cadernos.

Quanto à formação do ator, os Cadernos podem agir em duas direções. Primeiro, de modo indireto, trazendo um auxílio aos atores-aprendizes, ao darem indicações aos encenadores sobre os meios de trabalhar com eles. Em segundo lugar, diretamente, por meio de exercícios corporais ou vocais publicados, a serem experimentados individualmente ou em grupo; por jogos, por sugestões de improvisação; pela escolha de um repertório; por noções teóricas sobre o jogo, sobre o espaço, sobre as concepções dos homens de teatro, pelo despertar da curiosidade com relação a todos os aspectos componentes de um espetáculo teatral, visto numa perspectiva de coletividade, de disciplina, de rigor mas também de prazer de ser um servidor da arte dramática.

Além dos exercícios práticos (voz, corpo, improvisação) para o ator, OS . 
Cadernos publicam os testemunhos de atores e textos teóricos sobre seu ofícioO que ressalta dessas colaborações é uma idéia de dinamismo, de textos acessíveis e agradáveis, dando vontade de buscar, de ler, de "ir além”. Esses cadernos podem, aliás, ser lidos em vários níveis. Nas grandes cidades, as pessoas interessadas encontrarão neles um ponto de partida para descobrir e continuar a procurar.

Encontrando, por exemplo, um trecho de Barba, de Grotowski, de Strehler, de Copeau, procurarão saber mais, irão à biblioteca ou a livreiros especializados, para comple(men)tar sua leitura. Nas cidades pequenas, esses artigos podem prover uma necessidade imediata, e criar o impulso de encomendar livros, de escrever a universidades ou a pessoas que possam eventualmente suprir um desejo de saber. Tudo isso cria um movimento dinâmico, uma procura maior de informação e de formação - não só pelo pedido de informações, mas também pela experimentação das informações na prática, por tentativas, por esboços que às vezes originam espetáculos dirigidos a determinada comunidade e que, assim, desempenham um papel descentralizador.

A fecundidade maior do trabalho de Maria Clara Machado (e sua equipe) reside no fato de que, a partir do contato com a obra de Chancerel, ela não se limitou a traduzir os periódicos franceses: fez uma seleção, viu o que se adaptava à realidade que ela estava vivendo no Brasil e desejava compartilhar. Os Cahiers lhe proporcionaram meios de concretizar a necessidade de ser útil, de se voltar para as regiões mais isoladas e levar-lhes não o teatro mas a sua centelha, de ser útil, de "servir", de "jogar bíblias de avião", de realizar utopias e continuar a criá-las. Com a ação de Maria Clara Machado ${ }^{9}$ e de toda a equipe d'O Tablado, os Cahiers traduzidos puderam passar a ser, plenamente, Cadernos. Longa vida a eles! As gerações se sucedem e se superam. O amor ao teatro segue seu curso.

\footnotetext{
${ }^{9}$ Personalidade forte, Maria Clara Machado sempre soube muito bem o que deseja ver publicado pelos Cadernos de Teatro. É elogiável, porém, que ela tenha sempre tido em conta a equipe com que trabalha. É sintomático que as publicações de Chancerel contivessem a menção de que ele era o seu fundador e diretor. Já ao pensar nos Cadernos de Teatro, embora creditando à sua fundadora todo o seu valor, vem logo à lembrança de que se trata de uma publicação do grupo teatral O Tablado. Tal atitude foi projetada por ela, por ela arquitetada e obtida. Afirmando a importância de sua participação, a clareza e força de seus princípios, Maria Clara Machado sempre valorizou o espírito coletivo no teatro e particularmente no periódico em que pôs nele o seu grande entusiasmo. Com ele começou a construir, ao longo dos últimos quarenta e cinco anos, uma parte (considerável) da obra - convivendo, como no poema de Carlos Drummond de Andrade, na praça de convites.
} 


\section{Bibliografia:}

BAYEN, Maurice. 1945. L'École d'Arlequin. Paris: L'Arc Tendu.

BULLETIN DES COMÉDIENS ROUTIERS D'ÎLE DE FRANCE. 1932. Paris, ano 1, n. 1, nov.

1933a. Paris, ano 1, n. 7-8, fev.

1933b. Paris, ano 2, n. 14, mai-jun.

CADERNOS DE TEATRO. 1956. Publicação d'O Tablado, Rio de Janeiro, ano 1, n.1. CAHIERS D'ART DRAMATIQUE. 1950. Publicação da Association Centre Dramatique,

Paris, ano 12 n. 3, out-dez.

CHANCEREL, LÉON. 1936. Introduction à una Méthode, em CHARBONNIER-JOLY \&

SAUSSOY-HUSSENOT, Anne-Marie. "Jeux dramatiques" dans Éducation.

Paris: Théatrale. Col. Théâtre et Pédagogie.

1948. Comment monter et présenter un spectacle de qualité, em Cahiers d'Art

Dramatique. Publicaçõa da Association Centre Dramatique, ano 10, n. 5, jun.

COPEAU, Jacques. 1974. Appels. Registres I.Paris:Gallimard.

DULLIN, Charles. 1946. Techniques Élémentaires du Comédien, em Souvenirs et notes de travail d'un acteur. Paris: Odette Lieutier. Em Cardenos de Teatro, publicação

d'O Tablado, Rio de Janeiro: ano 1, n. 2 [1956].

FALEIRO, José Ronaldo. 1988. La Formation de l'Acteur à partir des Cahiers d'Art Dramatique de Léon Chacerel et des Cadernos de Teatro d'O Tablado. (Tese de Doutorado em Artes do Espetáculo.

Sob direção de Robert Abirached / Univesité de Paris XX - nanterre).

GARRONE, Louis. 1938. Théâtre au Collège. Em Art Dramatique. Bulletin du centre d'Études et de Représentations. Paris, ano 6, v. 4-5, abr-mai.

HUSSENOT, Olivier. L'Art du Masque. Pour et Contre le Masque. Em Bulletin des Comédiens Routiers d'île de France. Paris, ano 1, v. 1, nov.

1978. Ma Vie Publique en Six Tableaux. Paris:Denoël.

MACHADO, Maria Clara. 1991. Eu o o Teatro. Rio de Janeiro: Agir.

MAGNO, Paschoal Carlos. 1952. Correio da Manhã. Em Dionisyo, 10 de set.

1986. O Tablado. Rio de Janeiro:INACEN/MinC.

SEBASTIEN. 1932. Feuilles de Route. Em Bulletin des Comédiens Routier d'île de France, ano 1, n. 7-8, mai-jun.

VEINSTEIN, André. 1955 Du Théâtre Libre au Théâtre Louis Jouvet. Les

Théâtres

Gouhier). Paris
d'Art à Travers leurs Périodiques. (Prefácio de Henri Théâtrale.

VICENT, Claude. 1955. Tribuna da Imprensa. Em Dionisyo, maio.

1986. O Tablado. Rio de Janeiro: INACEN/MinC. 